\title{
Rewriting the Narrative: An Anti-Deficit Perspective on Study Abroad Participation
}

\author{
Christel Perkins \\ Association of Public and Land-grant Universities
}

\begin{abstract}
:
Higher education literature has often documented the barriers to participation in study abroad for students of color. However, the majority of study abroad research to date employs a deficit frame, focusing on why students of color do not participate, rather than on what enables students of color to rise above barriers. Using an anti-deficit orientation, this study analyzed the survey responses of a sample of students of color who studied abroad, in order to highlight the self-reported motivational and influential factors present in their decision-making process. Building on previous applications of the integrated college choice model (Salisbury et al., 2011), and informed by Yosso's (2005) community cultural wealth model, this article presents a new conceptual framework for understanding how students of color use forms of capital to enable them to study abroad. Implications and practical suggestions for future research and study abroad administration are described in light of the study's findings.
\end{abstract}

\section{Introduction}

The exponential growth in study abroad participation among students from U.S. colleges and universities over the past century can be attributed to many factors, including an increased emphasis on internationalization in higher education (Altbach \& Knight, 2007), a geopolitical climate that enables some individuals to move across borders at a faster pace, and the large body of research that demonstrates that study abroad is an academic endeavor with significant impacts for students academically, personally, and professionally (DeGraaf, Slagter, Larsen, \& Ditta, 2013; Jochum, 2014; Li, Olson, \& Frieze, 2013; Liu, 2010; Walker, Bukenya, \& Thomas, 2011; Williams, 2005). Despite the rise in participation nationwide, data indicates that students of color are not keeping pace with their White peers (Institute of International Education [IIE], 2019). According to IIE's Open Doors Report (2019), in academic year 2017-18, approximately $70 \%$ of study abroad participants were White, 11\% Hispanic/Latino(a), 8\% Asian or Pacific Islander, 6\% Black or African American, ${ }^{1} 4 \%$ Multiracial, and less than 1\% American Indian or Alaska Native. Unfortunately, this gap has been narrowing at a slow pace, despite the efforts of study abroad administrators and researchers to highlight underrepresentation among students of color.

The majority of study abroad underrepresentation research to date is framed from a deficit perspective. That is, research primarily centers on some variation of the question 'Why don't students of color study abroad?" Much has been written about the barriers to participation (Brux \& Fry, 2010; Dessoff, 2006; Simon \& Ainsworth, 2012), challenges students of color face while abroad

\footnotetext{
1 Throughout the article, the reader will note the varying use of the terms Black, African American, and Black/African American, as well as Hispanic and Latino(a). In an effort to keep the fidelity of the data as originally presented in the literature, the author used the exact terms utilized in source documents.
} 
(Penn \& Tanner, 2009; Willis, 2015), and the likelihood or intent to study abroad (Salisbury, Paulsen, \& Pascarella, 2011). While these insights are valuable, deficit orientations in higher education research fail to consider aspects of students of color's pre-college lives, college experiences, and engagement opportunities that they identify as instrumental in surmounting barriers (Harper, 2012; Harper, Berhanu, Davis, \& McGuire, 2015). As a result, research on students of color and study abroad lacks a recognition of and appreciation for the many forms of capital that students of color possess, value, and rely upon in order to successfully navigate the decision to study abroad. Utilizing Yosso's (2005) community cultural wealth model as a guiding paradigm, I propose that research on study abroad should challenge the dominant narrative on students of color by employing research designs and analytical approaches that are explicitly anti-deficit. Exemplifying this narrative shift, this study was framed around the question "Why do students of color study abroad?" Its intent was to explore the factors that motivated students of color to pursue studying abroad, and the factors that were influential in solidifying their decision.

\section{Relevant Literature}

The Institute of International Education's (IIE) (2019) most recent academic year data shows that $2 \%$ of undergraduate students at U.S. colleges and universities studied abroad. As outlined above, less than one-third (30\%) were students of color (IIE, 2019). Although the numbers of students of color studying abroad have increased over the past decade, Hispanic/Latino and Black/African American students remain underrepresented when compared to the total population of undergraduate enrollees (National Center for Education Statistics [NCES], 2018).

\section{Barriers}

Conceptualizing this phenomenon as an access issue, scholars thus far have sought to increase participation among students of color by investigating and articulating their barriers to participation. The majority of research, to be summarized here, highlights four barriers: lack of information about programs, financial concerns, fear of racist encounters, and a lack of social and cultural capital.

\section{Lack of information.}

Early studies centered on the presumption that students of color were largely unaware of study abroad opportunities (Dawson, 2000; Dessoff, 2006; Solaun, 2003; Williams, 2007). Studies showed that study abroad administrators ranked lack of information about program offerings as a significant barrier, particularly for African American students (Dawson, 2000; Solaun 2003; Williams, 2007). However, when directly surveying students who did not study abroad, Hembroff and Rusz (1993) concluded that African Americans were only slightly less knowledgeable than Whites about available programs, while Penn and Tanner (2009) found that the majority of Black students were indeed informed about study abroad opportunities at their institution.

\section{Financial concerns.}

Research shows that regardless of race or ethnicity, college students report finances as a potential barrier to participating in study abroad programs (Vernon, Moos, \& Loncarich, 2017). This is felt even more intensely by low-income students, who are less likely to pursue studying abroad than their middle- to upper-income peers. (Salisbury, Umbach, Paulsen, \& Pascarella, 2009; Salisbury et al., 2011). According to the most recent data available, $72 \%$ of all Black and $60 \%$ of all Hispanic full-time undergraduate students received Pell Grants, as compared to only 34\% of their White 
peers (NCES, 2019). This intersection between race/ethnicity and low-income status is important to consider when framing conversations around students of color and studying abroad. Salisbury et al. (2009) found that low-income students who received financial aid intended on studying abroad at lower rates than students who do not receive financial aid. Although in many cases federal financial aid can be used to cover study abroad tuition costs (Dessoff, 2006; Whatley, 2017), a study of freshmen at an HBCU (Historically Black College or University) indicated significant financial concerns about study abroad in addition to inaccurate perceptions regarding the cost of participation (Penn \& Tanner, 2009).

Whether or not study abroad is truly financially out of reach, one of the greatest deterrents for students of color is the perception that there will be financial implications for participating (Chama, Ramirez, \& Mutepa, 2018; Fels, 1993; Hembroff \& Rusz, 1993). Students at an HBCU indicated that lack of institutional funding opportunities was a significant barrier to considering completing an internship abroad (Chama et al., 2018). Participants in that study highlighted financial needs in addition to tuition or fees, including travel costs and spending money (Chama et al., 2018). It is important to note that not only are students concerned about additional costs, they are concerned about their inability to earn money while abroad (Fels, 1993; Hembroff \& Rusz, 1993). Exemplifying this, Hembroff and Rusz (1993) polled students on the factors contributing to their decision to not participate in a study abroad program. Although the leading reasons for all students were that they could not afford a program or they needed to hold a summer job, the percentages for African Americans were the highest of all surveyed groups (Hembroff \& Rusz, 1993). This mirrored the findings in Fels's (1993) study in which participants identified the potential loss of income for their families as a barrier to participation.

Fear of racism abroad.

A second barrier often described in research is the assumption by students of color of difficult cross-cultural interactions, that is, racist encounters. According to Anderson Hubbard and Lawton (2015), some of what draws students to go abroad include "world enlightenment" and personal growth, i.e., the opportunity to experience new places and cultures, and develop personally as a result. However, research highlights a perceived fear that studying abroad would result in experiences with racism or discrimination (Brux \& Fry, 2010), or highlights negative encounters, such as Talburt and Stewart's (1999) description of an African American female's experience navigating racialized environments both inside and outside of the classroom while abroad in Spain. While negative encounters could happen in any given cross-cultural setting, early literature pointed to Blacks and African American students as particularly wary of this potential (Hembroff \& Rusz, 1993), and researchers theorized that their underrepresentation was, in part, a result of these fears (Dawson, 2000; Solaun, 2003).

Lack of social and cultural capital.

In the context of study abroad, researchers use the terms social and cultural capital to explore the connections that participants have with individuals (social capital) or previous exposure to beliefs or experiences (cultural capital) that give them knowledge or access to resources which predispose them to studying abroad or help them navigate the process of studying abroad (Salisbury et al., 2009; Salisbury et al., 2011; Simon \& Ainsworth, 2012). Salisbury et al. (2011) describe social capital as "the access to information through networks, support systems, and knowledgeable persons that 
can improve an individual's ability to investigate, navigate, and choose advantageous options or opportunities" (p. 126). Social capital is related to networks of people equipped with resources necessary to navigate access to and successfully obtain study abroad experiences. In summarizing the work of sociologist Pierre Bourdieu, Simon and Ainsworth (2012) described cultural capital as "general cultural background, knowledge, experiences, disposition, and skills that are transmitted from one generation to the next" (p. 3). That is, cultural capital is accumulated prior to college and is a result of familial access to elements that are deemed as favorable for participation in study abroad, such as having prior experience travelling internationally.

Hembroff and Rusz (1993) found that African American students were less likely than their White peers to have traveled internationally, nationally, or locally. Although not addressed through their data, the researchers conjectured as to whether this lack of experience traveling, which is a form of cultural capital, coincides with low rates of participation in study abroad. Simon and Ainsworth (2012) found that the absence of social and cultural capital factors (e.g., prior experience traveling abroad, parents' level of education) impacted the likelihood of low-income students and students of color studying abroad. When summing up their research findings, Simon and Ainsworth concluded that "poor and minority students are embedded in social networks that are less conducive to study abroad participation" (2012, p. 17). This conclusion finds fault in the networks of students of color and low-income students, framing them as lacking the "right types" of capital that enables students to study abroad. Rather than considering the wealth of assets found in communities of color (Yosso, 2005), previous research has solely focused on aspects of cultural and social capital possessed by and valued in White and high income communities (e.g., involvement in extracurricular activities, parent's occupational prestige) as indicative of study abroad participation (Salisbury et al., 2009; Salisbury et al., 2011; Simon \& Ainsworth, 2012).

\section{Benefits of Study Abroad}

Anecdotally, we know that study abroad administrators market programs to students by highlighting the benefits of participation, the majority of which can be categorized as personal, academic, or career-oriented. There is a body of research to validate these claims (DeGraaf et al., 2013; Dwyer, 2004), however, the majority of studies consider study abroad alumni as a whole, without mention to nuances and differences possible among participants of color.

Personal.

One of the most frequently researched personal benefits is increased intercultural sensitivity (Clarke, Flaherty, Wright, \& McMillen, 2009; Medina-Lopez-Portillo, 2004; Williams, 2005). Intercultural sensitivity, also referred to as intercultural communication or learning, describes the developmental process through which individuals are able to conceive of and reconcile cultural differences (Bennett, 1993; Medina-Lopez-Portillo, 2004). Clarke et al. (2009) define intercultural sensitivity as "the knowledge, skills, and attitudes/beliefs that enable people to work well with, respond effectively to, and be supportive of people in cross-cultural settings" (p. 174), while Kitsantas (2004) noted that intercultural sensitivity is a 21 st century skill of high value to college students. Research indicates that study abroad programs can be designed to foster opportunities for students to encounter and confront cultural differences (Demetry \& Vaz, 2017). While some studies focus on increased scores on intercultural sensitivity scales (Martinsen, 2011; Terzuolo, 2018), others use qualitative methods to articulate students' perception of impact (Covert, 2014). 
Academic.

Considering that the history of study abroad from U.S. universities has its roots in language study (Hoffa, 2010), it is not surprising that the literature on academic outcomes is dominated by research on language acquisition (Yang, 2016). Topics of exploration include the impact of studying abroad on oral competency (Jochum, 2014), written competency (Perez-Vidal \& Juan-Garau, 2009), and language proficiency (Burns, Rubin, \& Tarrant, 2018; Liu, 2010). Outside of language learning, research on academic benefits is less frequent, but provides important insight into perceived impacts of studying abroad (Dwyer, 2004; Ruth, Brewis, Blasco, \& Wutich, 2019). In a national survey of over 17,000 study abroad alumni, Dwyer (2004) reported that $80 \%$ felt studying abroad enhanced their academic experience, while $87 \%$ believed that their study abroad participation impacted subsequent educational experiences in their college careers. Ruth et al.'s (2019) study pointed to important gains in research-related skills, as well as a deepened understanding of the scientific research process among participants in a global health study abroad program.

\section{Career.}

Literature on the impact of study abroad on participants' careers is small, though growing, as it requires either longitudinal research designs or retrospective reporting (Dolby, 2007; Dwyer, 2004; Norris \& Gillespie, 2009; Thompson, 2004). Regardless of the approach, the research indicates that study abroad alumni tend to: (a) believe the experience influenced their career path (Ruth et al., 2019); (b) pursue job settings that are international or multicultural (Dwyer, 2004; Paige, Fry, Stallman, Josie, \& Jon, 2009); and (c) believe their experiences are valuable to potential employers (Franklin, 2010).

\section{Conceptual and Theoretical Frameworks}

Salisbury et al.'s (2011) application of Perna's (2006) integrated college choice model to minority student intent to study abroad provided a theoretical framework in which to situate this study's work. According to Salisbury et al. (2011), factors that influence the decision to study abroad are categorized as: 1) human and financial capital; 2) pre-college social and cultural capital; and 3) institutional context-related social and cultural capital acquisition. Based on Salisbury et al.s (2009) use of the integrated college choice model with majority and minority student population, the 2011 application also used logistic regression analysis to correlate the possession of aspects of four types of capital (human, financial, social, and cultural) to intent to study abroad. In both studies, human capital was defined as academic achievement in the form of ACT/SAT scores (Salisbury et al., 2009; Salisbury et al., 2011). For financial capital, the researchers used the variables indicating receipt of federal grants, loans, and institutional grants as indicators of study participants' financial context, ability to pay for costs associated with studying abroad, and whether they were likely low-income (Salisbury et al., 2009; Salisbury et al., 2011). Social and cultural capital are distinct but interrelated concepts as described above. Salisbury et al.'s (2011) analysis used results from four scales to comprehensively describe pre-college cultural and social capital acquisition: attitude toward literacy, involvement in high school (curricular activities), openness to diversity, and importance of personal and career success. Finally, institutional context-related social and cultural capital acquisition were defined using variables indicating institution type, program of study, and a scale measuring engagement during the first year (Salisbury et al., 2011). 
The model is an important contribution to the literature as it was one of the first times researchers attempted to connect forms of capital to study abroad participation. However, the model is not enough; forms of capital have yet to be articulated from the perspective of study abroad alumni of color. The integrated choice model paints a picture of the likelihood of studying abroad, but it does not: 1) use a sample of students who completed study abroad programs, 2) employ an anti-deficit orientation, 3) describe what students of color use to overcome barriers to participation, or 4) articulate the value that students of color place on studying abroad. Though the model was arguably not designed to meet the elements described above, framing studies in quantitative means only leaves out the voices of students of color.

To assist in the framing of this study, elements of Yosso's (2005) community cultural wealth model are used to demonstrate an anti-deficit approach to studying students of color and study abroad. A critical lens meant to challenge the narrative that achievement gaps in education exist because students of color lack the cultural capital needed to succeed, community cultural wealth focuses on six types of capital that communities of color exhibit, value, and bring to educational spaces. Yosso (2005) argued that students of color, and the communities from which they come, are indeed equipped with capital that enable them to succeed in society and in educational settings, although these forms of capital are often overlooked or undervalued by researchers and practitioners. Aspirational capital is the ability of people of color to transcend obstacles (both real and perceived) while imagining "possibilities beyond their present circumstances, often without the objective means to attain those goals" (Yosso, 2005, p. 78). Linguistic capital refers to the countless skills and expertise that people of color possess when they communicate in and navigate through various linguistic and cultural settings (Yosso, 2005). According to Yosso (2005), familial capital is both the connection itself to kin and the community, and a collection of knowledge resulting from relationships with kin (immediate and extended family members, friends, and community members). Social capital, in the context of community cultural wealth, is comprised of social networks that "can provide both instrumental and emotional support to navigate through society's institutions" (Yosso, 2005, p. 79). Yosso (2005) also notes the multi-directional nature of the networks for students of color - as individuals progress through these unfamiliar institutions, they disseminate important resources back to their communities and networks. As students of color find themselves in educational settings unfriendly toward and unappreciative of their values and communities, they are often able to rely upon their navigational capital to remain resilient and excel despite the institutionalized racist structures (Yosso, 2005). Finally, resistant capital exemplifies the ways that students of color leverage oppositional acts, behaviors, and perspectives to challenge dominant racialized narratives and work toward social and racial justice (Yosso, 2005).

Considering the wealth of capital that students of color possess and bring with them to college is critical to considering the experiences of students of color who participate in study abroad programs. Most relevant to the research presented in this article are Yosso's (2005) concepts of aspirational, familial, social, and navigational capital. It is important to consider what resources students of color possess that moved them from intent to study abroad to participation (i.e., aspirational capital, familial capital). Additionally, focus should be placed on the connections that assisted students of color in the decision-making process (i.e., social capital). Furthermore, critical examination of how students navigate institutional processes in order to actualize their study abroad 
experience (i.e., navigational capital) is needed to advance research in this area. Taking these challenges in mind, this study asked the following research questions:

1. What motivates undergraduate students of color to study abroad?

2. What do undergraduate students of color perceive as the most influential factor in their decision to study abroad?

In order to achieve this goal, a new conceptual framework for study abroad participation was created that would emphasize forms of capital used by study abroad alumni of color.

Figure 1. Conceptual Framework for the Decision to Study Abroad for Students of Color

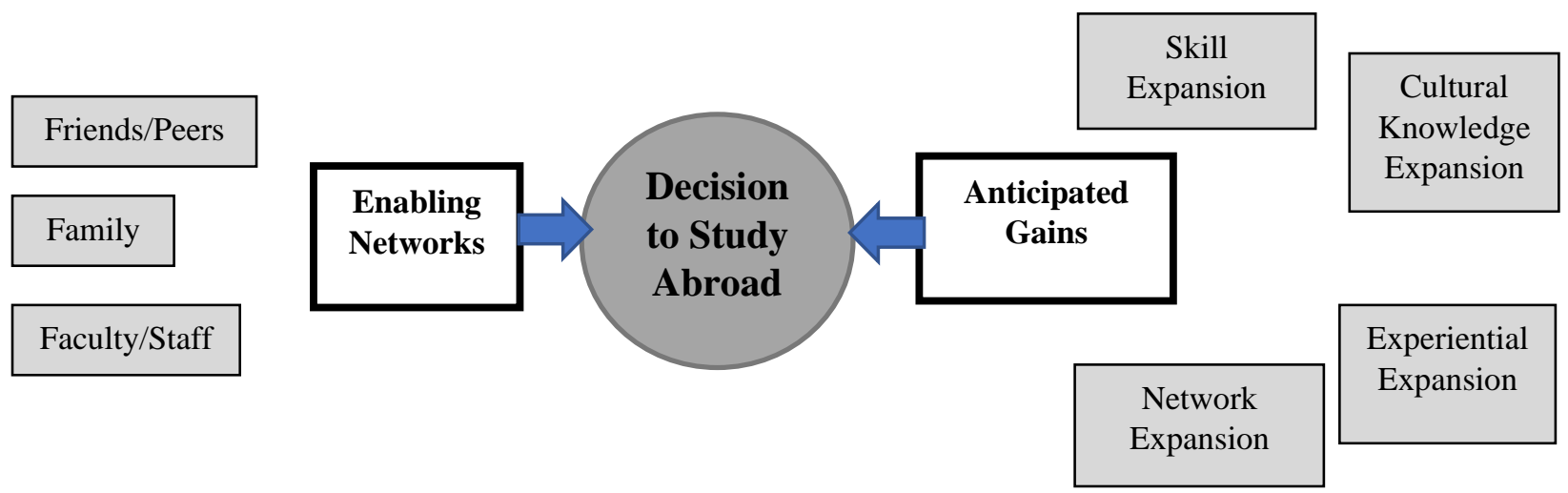

The framework above highlights the role that forms of capital play in the decision to study abroad for a sample of students of color. Integral to the decision to study abroad are Enabling Networks - individuals, groups, and relationships that lend social capital to the decision maker-and Anticipated Gains - the perceived increased social and cultural capital to be acquired by the decision maker. Research has well articulated financial capital as an important factor needed to study abroad and as a result, financial capital is not covered in the scope of this study, although its absence is not an indication that it lacks importance to students of color. Because the use of forms of capital has yet to be deeply explored, particularly from a qualitative research design, this framework presents an opportunity to sharpen the narrative around students of color participating in study abroad programs.

\section{Method}

This study includes a sample of study abroad alumni (current students and recent graduates) from two urban universities in the Mid-Atlantic region of the United States. To receive the study survey, individuals must have participated in a program that was credit-bearing and within the study window (academic years 2012/13-2015/16). Limits were not placed on the length of the study abroad experience, that is, students who studied abroad for as short as one week or as long as an academic year were eligible for participation. Study abroad administrators at both sites informed the researcher that they did not have the capability to determine race or ethnicity from their data management system. This indicates a lack of priority that some universities place on collecting and disaggregating data on their study abroad participants, and highlights a missed opportunity to 
provide data-driven narratives surrounding study abroad participation for students of color. Consequently, the lack of disaggregation made it necessary for the surveys to be sent to the entire population of study abroad alumni, with a question included that asked respondents to indicate their racial/ethnic backgrounds. For the purpose of this study, students of color are defined as participants who self-identified in one of the following categories: African American/Black, Alaskan Native/Pacific Islander, Arab/Middle Eastern, Asian, Hispanic/Latino/a, More than one race/ethnicity, Native American, or Other.

Surveys were sent to 3,168 study abroad alumni across both universities. Ninety-nine (99) individuals responded to the survey, and 52 of them met the racial or ethnic inclusion criteria described above for analysis in this study. While this represents only a two percent $(2 \%)$ response rate, this is due to the widened survey distribution rationale described above.

Table 1. Participant Demographics

Race/Ethnicity
African American/Black
Asian
Hispanic/Latino/a
More than one race/ethnicity
Arab/Middle Eastern
Other
Native American
Alaskan Native/Pacific Islander

Among other demographic and context-setting questions, the survey asked respondents three integral open-ended questions: "What motivated you to want to study abroad?", "How would you describe the single-most influential factor or element that impacted your decision to study abroad?", and "Please let me know of anything that I did not ask, but you feel would be beneficial for me to know about your pre-study abroad experiences." The responses to these questions were coded for themes using constant comparison analysis and classical content analysis. First, the researcher used constant comparison analysis, a foundational analysis technique used in grounded theory research, to create a set of codes related to the research questions (Boeije, 2002). As the name implies, constant comparison analysis is an iterative process whereby researchers relate codes to data and the data back to the already-created codes. Tesch (1990), describing the process in detail, indicates that researchers are purposeful in:

forming categories, establishing the boundaries of the categories, assigning the segments to categories, summarizing the content of each category, finding negative evidence, etc. The goal is to discern conceptual similarities, to refine the discriminative power of categories, and to discover patterns. (p.96)

Following these principles, the researcher arrived at six themes with 34 related subthemes.

Second, the researcher used classical content analysis to determine the frequency with which the subthemes were found throughout the data. Leech \& Onwuegbuzie (2007) indicate that this form of data analysis can assist researchers trying to identify the codes that hold the most value across the dataset. Researchers use this technique to tally the total number of times a theme occurs, and use 
that frequency as an indicator of the importance of that code to the overall findings (Leech \& Onwuegbuzie, 2007). The findings described below reflect the most frequently expressed thematic codes. What this represents is the emphasis that survey respondents placed on factors that motivated them to consider studying abroad, and the factors that influenced their decision. The reader will note that finances are not described in the findings below. This, however, does not mean that finances were not of concern or value to study participants, but rather that financial-related elements in the decision-making process did not rise above the other capital-related elements to be discussed here.

Finally, it is important to briefly describe the researcher's positionality in relationship to the research study. Qualitative researchers are expected to consider the ways that elements of their identity might influence the research process, referred to as researcher positionality (Milner, 2007). The author of this article is an African American woman who studied abroad as an undergraduate student. As a person of color, she navigated many of the well-researched barriers to participation for students of color described above. As a study abroad alum, she often reflected upon the factors that motivated her to pursue studying abroad, and the forms of capital that enabled her to achieve that goal. Because the researcher is intimately familiar with the research phenomenon (studying abroad as a student of color), she possesses an emic (insider) perspective that has the potential to either clarify or bias analysis and interpretation of findings (Patton, 2002). To control for this potential for personal bias, the author kept a researcher journal, a common technique in qualitative research (Ahern, 1999). By separating out one's personal experiences from the research phenomenon in a journal, the researcher is better positioned to transcend tendencies to rely on preconceived notions and focus more acutely on the data as presented (Ahern, 1999).

\section{Findings}

Upon review of the data, four thematic codes emerged most frequently, which can be summarized in two meta categories: Enabling Networks, and Anticipated Gains. Enabling Networks refers to a collection of people, and relationships with those people, that supported the decision to study abroad, and Anticipated Gains to the self-reported benefits that participants perceived they would reap by studying abroad. Both categories will be described in detail below using examples from participant responses. Community cultural wealth will be used to frame the analysis and discussion of findings.

\section{Enabling Networks}

Study participants frequently identified individuals who inspired them to go abroad or whose emotional support made the decision to study abroad easier. As a result, the presence of these players in one's social network allowed some students of color to leverage these relationships, their experiences, or access to resources to participate in a study abroad program. Examples of network players include family members, friends (outside of their university), peers (within the university), study abroad administrators, other university staff (advisors, student life staff), and faculty. Participants frequently responded that people with which they had the closest relationships (family, friends, and peers), had the most significant impact on their decision to study abroad. Table 2 shows the frequency of mention of network members after textual analysis. 
Table 2. Frequency of Mention, Network Enablers

$\begin{array}{lll}\text { Social Network Members } & \text { Frequency of Mention } & \text { Percent of Responses } \\ \text { Family } & 15 & 55 \% \\ \text { Peers/Friends } & 9 & 33 \% \\ \text { University Staff/Faculty } & 3 & 11 \%\end{array}$

It is interesting to note that although social capital-framed research indicates that individuals benefit from members with access to or who are a part of hierarchical structures (those with 'power' or in this case, university staff and faculty) (Salisbury et al., 2009; Simon \& Ainsworth, 2012), students of color in this study place only a small emphasis on these relationships as influential or motivational in their decision to study abroad. Rather, it is the supportive or motivational bonds gained from family and peers that are of primacy, which aligns with earlier discussions of familial capital (Yosso, 2005).

Family.

For some participants, family members who had prior international experiences had a significant impact on their desire to pursue the same:

My mother ... studied in Spain when she was in school and she wanted to provide me with a similar unforgettable experience. (Participant 45)

My older brother studied abroad in college and had a great time. (Participant 38)

My mom [was the most influential factor] because she finished her undergraduate degree [in] Tokyo. (Participant 29)

My entire family is from Sierra Leone and can speak to [a] way of life in several countries and I wanted that same ability. (Participant 11)

However, even when family networks did not provide social capital as a result of prior experiences, simply having members in the family network who supported the idea of one studying abroad proved instrumental in motivating participants. In fact, family support emerged as crucial to deciding to go abroad. For example, Participant 16 believed, "The single most influential factor that impacted my decision was the way my family supported me throughout the whole process." Furthermore, it appears that without support from their family networks, some students of color would not consider pursuing study abroad to completion. In the case of one participant,

When I first mentioned to my parents [that] I wanted to study abroad, they weren't initially that supportive. ... Then one day, they decided that they were for it. Once they fully supported the decision, we were able to start really planning for me to go abroad. (Participant 21)

In sum, accessing the social and familial capital and support already existing in students' networks is beneficial to the study abroad decision-making process.

Friends and peers.

Participants also indicated that the experiences of friends and other students inspired them to pursue their own study abroad journeys: 
When I first heard about study abroad I was simply interested but not sure if I would actually do it. But one of my friends actually did it and her experiences motivated me to strive for it and do it. (Participant 16)

Participant 38 wrote that the most influential factor in the decision to study abroad was "talking to people who already stud[ied] abroad. They all had a great time and really encouraged me." When returnees shared their experiences with the participant, they provided a positive narrative about studying abroad and as a result, supported the participant in the decision-making process. Participant 38 indicated heavy reliance on the recommendation of peers as motivation to move forward with the decision to study abroad.

University staff/other.

Although mentioned far less frequently than family and peers, university administrators (study abroad staff, and advisors) appear to provide some support and/or motivation for students of color to study abroad:

Study abroad staff shared her knowledge [about] the country with me . . I I was definitely [convinced to go] at that moment. (Participant 40)

My favorite professor pushed it so hard and gave me the confidence to apply for the program. (Participant 10)

It is interesting to note the lack of reliance on faculty as a motivator. Only one participant indicated that faculty fervor for a particular country or program solidified existing interest in studying abroad. Survey participants found motivation for studying abroad through their relationships with others. These individuals pushed them toward studying abroad or supported them in a manner that allowed them to feel confident in their decision to pursue study abroad.

\section{Anticipated Gains}

Not only are students of color relying on their networks to support and influence their decision to study abroad, they are doing so to achieve goals that relate to further expansion of their social networks, and obtainment of social and cultural capital. Examples of anticipated gains include satisfying a desire to travel to different countries (experiential expansion), learning about a new culture (cultural knowledge expansion), developing academic skills (skill expansion), and meeting new people (network expansion). These goals mirror aspirational capital as described in the community cultural wealth model (Yosso, 2005).

Table 3. Frequency of Mention, Anticipated Gains

$\begin{array}{lll}\text { Goal } & \text { Frequency of Mention } & \text { Percent of Responses } \\ \text { Network Expansion } & 8 & 8 \% \\ \text { Skill Expansion } & 16 & 17 \% \\ \text { Cultural Knowledge Expansion } & 30 & 32 \% \\ \text { Experiential Expansion } & 41 & 43 \%\end{array}$




\section{Experiential expansion.}

Participants were drawn to the opportunity that studying abroad would provide to travel internationally. Responses in this category did not include culturally-driven or lesson-learning motivations. Rather, these participants simply wanted to visit a new place. Responses under this subtheme were generally brief, such as "I honestly just wanted to travel," "I wanted to get out of the USA," or "I was most influenced by my desire to see the world on my own."

Within this group of travel-seekers, there was an undertone of urgency. Some expressed a desire to travel because they felt that they may not have this opportunity again in life, or that college presented the optimal time to travel.

I love to travel but have not been able to get out of the country much, so I felt that this was my chance to. Especially before I have a job which doesn't allow me to go jetting off for a month! (Participant 5)

Similarly, Participant 25 stated, "You're constantly told that college is the best time to [study abroad], so I took a shot." Whether motivated by a perceived time limitation on their ability to travel or by a general interest in traveling outside of the United States, the desire to travel was a strong motivator for students of color to study abroad.

Cultural knowledge expansion.

Also prominent among study participants was the belief that studying abroad would expose them to people, cultures, worldviews, and practices that differ from those with which they are familiar. Throughout the survey responses, participants often mentioned wanting to expand their horizons, pointing to an intrinsic value that students of color place on transcending their current cultural context and forming new understandings of the world. For example, Participant 7 stated, "I always had a desire to explore and learn about other cultures. I knew there was more world to see besides Philadelphia." Similarly, Participant 27 recalled, "What impacted my decision to study abroad was to expand my horizon. Learn from another country what they do differently and similar to the U.S. and see what knowledge I could gain that would be useful back here."

These participants believed that there is much value in the experiences and contributions of those outside of the United State. A subset of them placed value on experiencing life outside of the country due to their own ethnic identities:

I believe coming full circle on life is experiencing and learning about all cultures and history, especially the legacy of the African diaspora all over the world. (Participant 12)

I knew that leaving the country could broaden my horizons and increase my cultural currency. Also as a woman of color it is so important for me to be as informed as possible and connect with other women of color around the globe. (Participant 1)

These quotes indicate the connectedness that students of color may wish to have with their racial or ethnic communities on a global scale. For these individuals, this meant learning about and interacting with people of a similar heritage as they are found around the world. There is evidence that students of color want to experience cultures and ways of life different from those that they are familiar with in the United States. 


\section{Skill expansion.}

The third most frequently mentioned anticipated gain, Skill Expansion, denotes study abroad program components that are intended to develop specific skills or expose students to skill-building opportunities. This encompasses curricular elements (e.g., language learning) and co-curricular opportunities (e.g., service-learning).

Some survey participants who were academically motivated to study abroad did so because of an interest in specific elements of their program. As in the literature, respondents in this study emphasized language learning as an anticipated gain from their study abroad experience. However, there is evidence that language learning can be sparked by a desire to connect to one's racial or ethnic heritage, per Participant 44, “As a Latina who doesn't speak Spanish fluently, language was my number one reason for pursing an opportunity abroad." Furthermore, studying abroad provided some students with the opportunity to further develop academic skills gained in preceding coursework.

What most encouraged me to go to South Africa was my research project. . . For our final project we had to choose a city ... a and report on an issue. I chose Johannesburg, South Africa, and looked at rape culture and gender-based violence among Black women there. . . . That ultimately propelled me to go to South Africa and further my research. (Participant 1)

Also of interest to students considering study abroad in this sample was access to experiential learning opportunities as a part of a program. While not a part of every study abroad program's structure, it is worth noting the value that students placed on being able to connect experiential learning to their classroom learning. This includes service-learning, volunteer opportunities, and internships, which students in this study viewed as drivers toward future career paths. Students of color look for elements in study abroad programs that will give them the opportunity to develop skills or to apply their learning outside of the classroom. These responses indicate that students of color are looking for an academic value-add to the study abroad experience, in addition to the opportunity to experience and learn from other cultures or to travel to new places.

Network expansion.

A final anticipated gain for study participants was an expanded network of peers. As already discussed, friends and peers served as important motivators for students to study abroad; similarly, respondents described opportunities to create new social bonds as drivers to participate in a study abroad program. While the majority of responses relayed the simple message "I want to meet new people," Participant 1 exemplified how these expanded networks hold additional value when they encounter and develop relationships with other people of color:

Being a Black woman growing up in an urban environment, I did not know many people who traveled. .. . As a woman of color, it is so important for me to be as informed as possible, and connect with other women of color around the globe. (Participant 1)

Study abroad literature often focuses on the barriers to participation for students of color, perpetuating a narrative that they lack social and cultural capital needed to pursue studying abroad. However, as demonstrated in the voices of this study's participants, students of color indeed possess, value, and rely on forms of capital that drive them toward participation. 


\section{Discussion and Implications}

This study offers a challenge to the deficit-oriented narrative prevalent in study abroad underrepresentation research. By design, this study sought to identify the networks, values, and benefits that motivated and ultimately influenced students of color to study abroad. Aligning with Yosso's (2005) description of community cultural wealth among communities of color, the data from this study illuminated the types of capital present among students of color that allowed them to surmount the well-documented barriers to study abroad participation. These findings have important implications for higher education administrators and future study abroad research.

Previous research identified a lack of social and cultural capital as a barrier to study abroad participation for students of color (Salisbury et al., 2011; Simon \& Ainsworth, 2012), however, participants in this study described factors that, in contrast, point to the use of networks and the promise of expanded access to cultural and social capital as influential enablers in the decision to study abroad. This is reminiscent of Yosso's (2005) analysis of how students of color use networks and resources to navigate unfamiliar and unfriendly institutional and educational settings. Respondents in the study identified familial support and encouragement-regardless of whether family members had previous international experience-as integral to the decision-making process. This stands in contrast to some research indicating students of color are at a disadvantage because of a lack of access to individuals with capital-forming experiences (Simon \& Ainsworth, 2012), and closely aligns with the value placed on kin relationships and knowledge via familial capital (Yosso, 2005). As a result, to ignore the reliance upon this connection is to undervalue the structures and relationships of importance to this subpopulation. Study abroad administrators should adopt strategies that acknowledge and leverage students' networks, including family. In doing so, they acknowledge the value that students of color place on familial and community connections as drivers of success and achievement in college (Herndon \& Hirt, 2004; Sandoval-Lucero, Maes, \& Klingsmith, 2014; Xiong \& Lam, 2013).

Second, data from this study suggested that students of color are influenced to participate in study abroad programs because of the promise of returned gains. This embodies Yosso's (2005) description of aspirational capital, as students of color employ its use in order to consider and achieve a future state that surmounts their barriers to achieving desired outcomes. Research describes the benefits of studying abroad, and attempts to make a connection between the myriad benefits and how they impact students' decisions to participate (Anderson et al., 2015; Kitsantas, 2004; Relyea, Cocchiara, \& Studdard, 2008). A small body of research is emerging that articulates motivation from the perspective of students of color (Kasravi, 2010; Lu, Reddick, Dean, \& Pecero, 2015; Perkins, 2017; Van Der Meid, 2003). Future research in this area is needed to deepen our understanding of the decision-making process for students of color.

The findings from this study can provide tangible insights for study abroad administrators. First, because students of color are enabled by their networks to participate, administrators may consider crafting their outreach to be more inclusive of students' families and peer groups. Colleges and universities already have practices of engaging parents throughout the academic year, such as parents' weekend events, tailored websites, and information campaigns. Adding information about study abroad opportunities and benefits for students may help enrich conversations with students who are considering participation. Leveraging students' other enabling networks, specifically peers, 
can also be instrumental in increasing participation. Many institutions already use study abroad alumni to serve as ambassadors to students considering participation; this practice appears to be effective and should be continued (Lo, 2006; Sweeney, 2014). Additionally, targeted outreach, including at multicultural centers, minority-serving fraternity and sorority organizations, livinglearning communities, and other student affairs organizations, provide opportunities for students of color to normalize participation among their peers.

Finally, more research employing anti-deficit lines of inquiry, and informed by the forms of capital prominent in communities of color, needs to be advanced in order to deepen and inform practice. This study is not without its limitations. The sample size is small, and readers may question its representation of the population of undergraduate students of color nationwide. Second, participants in this study attended one of two urban universities in the Mid-Atlantic region of the country, bringing to question whether regional or institutional mission particularities of the study sites may impact the generalizability of the responses. Third, the use of a survey, rather than interviews, may limit the ability to provide additional context among responses. Larger-scale, demographically representative studies that incorporate qualitative interviews will continue to help this topic evolve. Despite these limits, the study offers a new perspective on what enables students of color to overcome barriers and ultimately study abroad. If benefits of study abroad participation are truly for all 21 st century students, then research must continue to frame underrepresentation of students of color in study abroad as an equity issue that must be addressed comprehensively and be inclusive of the resources these students use to navigate educational spaces, structures, and opportunities designed without their strengths, values, and communities in mind.

\section{References}

Ahern, K. J. (1999). Ten tips for reflexive bracketing. Qualitative Health Research, 9(3), 407-411. doi: $10.1177 / 104973299129121947$

Altbach, P. G., \& Knight, J. (2007). The internationalization of higher education: Motivations and realities. Journal of Studies in International Education, 11(3-4), 290-305. doi: 10.1177/1028315307303542

Anderson, P., Hubbard, A., \& Lawton, L. (2015). Student motivation to study abroad and their intercultural development. Frontiers: The Interdisciplinary Journal of Study Abroad, 23, 39-52.

Bennett, M. (1993). Towards ethnorelativism: A developmental model of intercultural sensitivity. In M. Paige (Ed.), Education for the intercultural experience. Yarmouth, ME: Intercultural Press.

Boeije, H. (2002). A purposeful approach to the constant comparative method in the analysis of qualitative interviews. Quality and Quantity, 36(4), 391-409. doi: 10.1023/A:1020909529486

Brux, J., \& Fry, B. (2010). Multicultural students in study abroad: Their interests, their issues, and their constraints. Journal of Studies in International Education, 14(5), 508-527. doi: $10.1177 / 1028315309342486$

Chama, S., Ramirez, O., \& Mutepa, R. (2018). Perceived barriers to interning abroad: Perceptions from African American social work students. Journal of Student Affairs Research and Practice 55(3), 321333. doi: 10.1080/19496591.2018.1474751

Clarke, I., III, Flaherty, T. B., Wright, N. D., \& McMillen, R. M. (2009). Student intercultural proficiency from study abroad programs. Journal of Marketing Education, 31(2), 173-181. doi: $10.1177 / 0273475309335583$

Covert, H. (2014). Stories of personal agency: Undergraduate students' perceptions of developing intercultural competence during a semester abroad in Chile. Journal of Studies in International Education, 18(2), 162-179. doi: 10.1177/1028315313497590 
Dawson, N. J. (2000). Study abroad and African American college students at Southern Illinois University at Carbondale. African Issues, 28(1/2), 124-129. doi: 10.2307/1167074

DeGraaf, D., Slagter, C., Larsen, K., \& Ditta, E. (2013). The long-term personal and professional impacts of participating in a study abroad program. Frontiers: The Interdisciplinary Journal of Study Abroad, $23,42-59$.

Demetry, C., \& Vaz, R. F. (2017). Influence of an education abroad program on the intercultural sensitivity of STEM undergraduates: A mixed methods study. Advances in Engineering Education, $6(1), 1-32$.

Dessoff, A. (2006, March/April). Who's not going abroad? International Educator, 20-27.

Dolby, N. (2007). Reflections on nation: American undergraduates and education abroad. Journal of Studies in International Education, 11(2), 141-156. doi: 10.1177/1028315306291944

Dwyer, M. (2004). More is better: The impact of study abroad program duration. Frontiers: The Interdisciplinary Journal of Study Abroad, 10, 151-163.

Fels, M. D. (1993, November). Assumptions of African American students about international education exchange. Paper presented at the Speech Communication Association Convention, Miami, FL.

Franklin, K. (2010). Long-term career impact and professional applicability of the study abroad experience. Frontiers: The Interdisciplinary Journal of Study Abroad, 19, 169-190.

Harper, S. R. (2012). Black male student success in higher education: A report from the National Black Male College Achievement Study. Philadelphia: University of Pennsylvania, Center for the Study of Race and Equity in Education.

Harper, S. R., Berhanu, J., Davis, C. H., III, \& McGuire, K. M. (2015). Engaging college men of color. In S. Quaye \& S. Harper (Eds). Student engagement in higher education: Theoretical perspectives and practical approaches for diverse populations. New York, NY: Routledge.

Hembroff, L. A., \& Rusz, D. L. (1993). Minorities and overseas studies programs: Correlates of differential participation. New York, NY: Council on International Education Exchange.

Herndon, M., \& Hirt, J. (2004). Black students and their families: What leads to success in college. Journal of Black Studies, 34(4), 489-513. doi: 10.1177/0021934703258762

Hoffa, W. W. (2010). A history of US study abroad: Beginnings to 1965. Carlisle, PA: Forum on Education Abroad.

Institute of International Education (IIE). (2019). Open doors: 2019 fast facts. Retrieved from https://www.iie.org/en/Research-and-Insights/Open-Doors/Fact-Sheets-and-Infographics/Fast-Facts

Jochum, C. J. (2014). Measuring the effects of a semester abroad on students' oral proficiency gains: A comparison of at-home and study abroad. Frontiers: The Interdisciplinary Journal of Study Abroad, $24,93-104$.

Kasravi, J. (2010). Factors influencing the decision to study abroad for students of color: Moving beyond the barriers (Doctoral dissertation). University of Minnesota-Twin Cities, Minneapolis, MN.

Kitsantas, A. (2004). Studying abroad: The role of college students' goals on the development of crosscultural skills and global understanding. College Student Journal, 38(3) 441-452.

Leech, N. L., \& Onwuegbuzie, A. J. (2007). An array of qualitative data analysis tools: A call for data analysis triangulation. School Psychology Quarterly, 22(4), 557-584. doi: 1037/1045-3830.22.4.557

Li, M., Olson, J. E., \& Frieze, I. H. (2013). Students' study abroad plans: The influence of motivational and personality factors. Frontiers: The Interdisciplinary Journal of Study Abroad, 23, 73-89.

Liu, J. (2010). Assessing students' language proficiency: A new model of study abroad program in China. Journal of Studies in International Education, 14(5), 528-544. doi: 10.1177/1028315309337953

Lo, S. (2006). Defining the peer advisor in the US study abroad context. Journal of Studies in International Education, 10(2), 173-184. https://doi.org/10.1177/1028315305283305

Lu, C., Reddick, R., Dean, D., \& Pecero, V. (2015). Coloring up study abroad: Exploring Black students' decision to study in China. Journal of Student Affairs Research and Practice, 52(4), 440-451. doi: 10.1080/19496591.2015.1050032

Martinsen, R. (2011). Predicting changes in cultural sensitivity among students of Spanish during shortterm study abroad. Hispania, 94(1), 121-141. 
Medina-Lopez-Portillo, A. (2004). Intercultural learning assessment: The link between program duration and the development of intercultural sensitivity. Frontiers: The Interdisciplinary Journal of Study Abroad, 10, 179-199.

Milner, H. R. (2007). Race, culture, and researcher positionality: Working through dangers seen, unseen, and unforeseen. Educational Researcher, 36(7), 388-400. doi: 10.3102/0013189X07309471

National Center for Education Statistics. (2019). Table 331.35: Percentage of full-time, full-year undergraduates receiving financial aid, and average annual amount received, by type and source of aid and selected student characteristics: Selected years, 1999-2000 through 2015-16. Retrieved from https://nces.ed.gov/programs/digest/d18/tables/dt18_331.35.asp

National Center for Education Statistics. (2018). Table 306.10: Total fall enrollment in degree-granting postsecondary institutions, by level of enrollment, sex, attendance status, and racelethnicity or nonresident alien status of student: Selected years, 1976 through 2017. Retrieved from https://nces.ed.gov/programs/digest/d18/tables/dt18_306.10.asp

Norris, E., \& Gillespie, J. (2009). How study abroad shapes global careers. Journal of Studies in International Education, 13(3), 382-397. doi: 10.1177/1028315308319740

Paige, R., Fry, G. W., Stallman, E. M., Josie, J. \& Jon, J. (2009). Study abroad for global engagement: The long-term impact of mobility experiences. Intercultural Education (20)S1-2, S29-44. doi $10.1080 / 14675980903370847$

Patton, M. (2002). Qualitative research and evaluation methods (2nd ed.). Thousand Oaks, CA: Sage.

Penn, E. B., \& Tanner, J. (2009). Black students and international education: An assessment. Journal of Black Studies, 40(2) 266-282. doi: 10.1177/0021934707311128

Perez-Vidal, C., \& Juan-Garau, M. (2009). The effect of study abroad (SA) on written performance. EUROSLA Yearbook, 9(1), 269-295. doi: http://dx.doi.org/10.1075/eurosla.9.13per

Perkins, C. (2017). Students of color studying abroad: A qualitative description of the factors that influence participation and the perceived impact of participation (Doctoral dissertation). Available from Proquest Dissertations Publishing (Order No. 10276848)

Perna, L. W. (2006). Studying college access and choice: A proposed conceptual model. In J. C. Smart (Ed.), Higher education: Handbook of theory and research (Vol. xxi, pp. 99-157). New York, NY: Springer Press.

Relyea, C., Cocchiara, F. K., \& Studdard, N. L. (2008). The effect of perceived value in the decision to participate in study abroad programs. Journal of Teaching in International Business, 19(4), 346-361. doi: 10.1080/08975930802427551

Ruth, A., Brewis, A., Blasco, D., \& Wutich, A. (2019). Long-term benefits of short-term researchintegrated study abroad. Journal of Studies in International Education, 23(2), 265-280. doi: $10.1177 / 1028315318786448$

Salisbury, M. H., Paulsen, M. B., \& Pascarella, E. T. (2011). To see the world or stay at home: Applying an integrated student choice model to explore the gender gap in the intent to study abroad. Research in Higher Education, 51(7), 615-640. doi 10.1007/s11162-008-9111-x

Salisbury, M. H., Umbach, P. D., Paulsen, M. B., \& Pascarella, E. T. (2009). Going global: Understanding the choice process of the intent to study abroad. Research in Higher Education, 50(2), 119-143. doi: 10.1007/s11162-008-9111-x

Sandoval-Lucero, E., Maes, J. B., \& Klingsmith, L. (2014). African American and Latina(o) community college students' social capital and student success. College Student Journal, 48(3), 522-533.

Simon, J., \& Ainsworth, J. W. (2012). Race and socioeconomic status differences in study abroad participation: The role of habitus, social networks, and cultural capital. ISRN Education, 2012, 1-21. doi: $10.5402 / 2012 / 413896$

Solaun, J. (2003). Participation of minority and low income students in study abroad: The Illinois-NSEP initiative. In E. Hult \& G. Lashbrooke (Eds.), Study abroad: Perspectives and experiences from business schools. Oxford, UK: Elsevier. 
Sweeney, K. (2014). Race matters: An examination of the study abroad experience of African American undergraduates (Doctoral dissertation). Retrieved from ProQuest Dissertations and Theses Global (Order No. 1629825727)

Talburt, S., \& Stewart, M. (1999). What's the subject of study abroad?: Race, gender and "living culture". The Modern Language Journal, 83(2), 163-175. doi: 10.1111/0026-7902.00013

Terzuolo, E. R. (2018). Intercultural development in study abroad: Influence of student and program characteristics. International Journal of Intercultural Relations, 65, 86-95. https://doi.org/10.1016/j.ijintrel.2018.05.001

Tesch, R. (1990). Qualitative research: Analysis types and software. London, UK: Falmer Press.

Thompson, J. W. (2004). An exploration of the demand for study overseas from American students and employers. A report prepared for the Institute of International Education, the German Academic Exchange Service (DAAD), the British Council, and the Australian Education Office. Retrieved from www.nafsa.org/_/File/_/study_by_iie_daad_bc.pdf

Van Der Meid, J. S. (2003). Asian Americans: Factors influencing the decision to study abroad. Frontiers: The Interdisciplinary Journal of Study Abroad, 9(4), 71-110.

Vernon, A., Moos, C., \& Loncarich, H. (2017). Student expectancy and barriers to study abroad. Academy of Educational Leadership Journal, 21(1).

Walker, S., Bukenya, J. O., \& Thomas, T. (2011). Examining students' perceptions of globalization and study abroad programs. US-China Education Review, B(1), 77-88.

Whatley, M. (2017). Financing study abroad: An exploration of the influence of financial factors on student study abroad patterns. Journal of Studies in International Education, 21(5), 431-449. doi: $10.1177 / 1028315317697798$

Williams, T. R. (2005). Exploring the impact of study abroad on students' intercultural communication skills: Adaptability and sensitivity. Journal of Studies in International Education,9(4), 356-371. doi: 10.1177/1028315305277681

Willis, T. Y. (2015). "And still we rise...": Microaggressions and intersectionality in the study abroad experiences of Black women. Frontiers: The Interdisciplinary Journal of Study Abroad, 26, 209-230.

Xiong, S., \& Lam, S. Y. (2013). Factors affecting the success of Hmong college students in America. British Journal of Guidance \& $\quad$ Counselling, 41(2), 132-144. https://doi.org/10.1080/03069885.2012.713909

Yang, J. S. (2016). The effectiveness of study-abroad on second language learning: A meta-analysis. Canadian Modern Language Review, 72(1), 66-94. https://doi.org/10.3138/cmlr.2344

Yosso, T. J. (2005). Whose culture has capital? A critical race theory discussion of community cultural wealth. Race Ethnicity and Education, 8(1), 69-91. doi: 10.1080/1361332052000341006 